\title{
A IMPORTÂNCIA E IMPACTOS DA CERTIFICAÇÃO LEED (LEADERSHIP IN ENERGY AND ENVIRONMENTAL DESIGN) NA CONSTRUÇÃO DE CIDADES SUSTENTÁVEIS
}

\section{ARTIGO DE REVISÃO}

ZIMBRES, Roberto Forghieri Vernalha ${ }^{1}$

LIMA, Paulo Renato ${ }^{2}$

ZIMBRES, Roberto Forghieri Vernalha. LIMA, Paulo Renato. A importância e impactos da certificação LEED (Leadership in Energy and Environmental Design) na construção de cidades sustentáveis. Revista Científica Multidisciplinar Núcleo do Conhecimento. Ano 05, Ed. 06, Vol. 07, pp. 108-134. Junho de 2020. ISSN: 2448-0959, Link de

acesso: https://www.nucleodoconhecimento.com.br/arquitetura/impactos-dacertificacao

\section{RESUMO}

O modelo de desenvolvimento urbano praticado nas cidades de hoje é insustentável. O presente trabalho mostra uma poderosa ferramenta capaz de transformar cidades através de projetos, obras e operações com o intuito em sustentabilidade e propensão ambiental. Neste artigo através da certificação internacional LEED (Leadership in Energy and Environmental Design), objetivou-se mostrar e incentivar na busca de

1 Especialista em Gestão Urbana e Sustentabilidade, Especialista em Sustentabilidade na Construção Civil, Graduado em Arquitetura e Urbanismo pela Universidade Estadual do Maranhão.

2 Doutorado em andamento em Biotecnologia Ambiental. Mestrado em Biotecnologia Ambiental. Especialização em Biotecnologia Ambiental. Especialização em Ciências da Religião. Graduação em andamento em Filosofia. Graduação em Engenharia Ambiental. Graduação em Gestão Ambiental. 
transformar ou criar cidades verdes, inclusivas, resilientes e inteligentes, trazendo assim, benefícios econômicos, sociais e ambientais. No decorrer do trabalho foi abordado a tipologia Cidades e Comunidades Existentes, da qual possui 9 tópicos que foram analisadas dentre pré-requisitos (práticas obrigatórias) e créditos (recomendações). Constatou-se que a certificação em suas nove dimensões analisadas, transformam e criam cidades sustentáveis, levando deste modo, qualidade de vida aos seus cidadãos.

Palavras-chave: Cidades Sustentáveis, certificação LEED, desenvolvimento urbano.

\section{INTRODUÇÃO}

As cidades sustentáveis vêm sendo tema em escala internacional há quase 50 anos desde que a Organização das Nações Unidas (ONU) decidiu discutir o assunto no início de 1970 juntando um grande número de países em uma agenda global. Cidade sustentável em um conceito mais amplo seria a cidade que precisa cumprir com os seus objetivos ambientais, sociais, políticos, culturais e econômicos de seus cidadãos, buscando principalmente modelos de gestão e crescimento diferente do praticado no século $X X$ e neste início do século $X X I$, no que desrespeito ao esgotamento dos recursos. Devem-se adotar novos modelos de gestão urbana baseado no crescimento de forma eficiente onde não há esgotamento de recursos como a terra, água, alimento, energia e em todo o processo final, quanto aos resíduos, esgoto, poluição entre outros.

A mudança climática atualmente é o principal problema ambiental, social e econômico que o planeta enfrenta. Cada vez mais a população habita cidades, aumentando assim o consumo de energia e recursos naturais e consequentemente aumentando as emissões globais de CO2. Entramos no século $21 \mathrm{com}$ o desafio de um desenvolvimento sustentável, tentando aliar o desenvolvimento da economia com o não esgotamento dos recursos naturais do planeta.

De acordo com Jeffrey Sachs, diretor do Earth Institute da Universidade de Columbia, a atual trajetória ecológica, demográfica e econômica do mundo é insustentável, 
podendo assim, alcançar um crescimento econômico com impacto muito menor se pensarmos de forma clara, sistêmica e baseada em objetivos globais. (Sachs, 2008).

A certificação internacional LEED (Leadership in Energy and Environmental Design), é uma poderosa ferramenta para transformar cidades, através de projetos, obras e operações com o foco em sustentabilidade e orientação ambiental. A maneira como pensamos sobre edifícios, comunidades e cidades são planejadas, construídas e operadas está em constante mudança e evolução. A certificação traz também benefícios econômicos, sociais e ambientais. O objetivo principal do trabalho é mostrar a importância e o impacto positivo que a certificação LEED pode causar na criação de cidades sustentáveis, aplicando o sistema de certificação para a criação de cidades resilientes, verdes, inclusivas e inteligentes.

Existem seis tipologias aplicadas ao sistema LEED v4.1: $B D+C$ (Novas Construções), $I D+C$ (Design de Interiores), $O+M$ (Edifícios Existentes), Residencial, Cidades e Comunidades e Recertificação. O presente trabalho abordará a tipologia Cidades e Comunidades Existentes, da qual possui 9 dimensões para serem analisadas. Todas possuem pré-requisitos (práticas obrigatórias) e créditos (recomendações) que conforme são atendidos, asseguram pontos para a edificação. São elas, Processo Integrativo (IP), Sistemas Naturais e Ecologia (NS), Transporte e Uso da Terra (TR), Eficiência Hídrica (WE), Energia e Emissões de Gases de Efeito Estufa (EN), Materiais e Recursos (MR), Qualidade de Vida (QL), Inovação (IN) e Prioridade Regional (RP).

O intuito principal desta tipologia é planejar, projetar, medir e gerenciar o desempenho de condições sociais, econômicas e ambientais em nível municipal ou comunitário. As cidades e as comunidades certificadas pelo LEED são lugares saudáveis e sustentáveis que as pessoas irão adorar viver. Irá abranger a sustentabilidade, a qualidade de vida, saúde, prosperidade, equidade, acesso, capacitação, segurança, educação, resiliência, infraestrutura e energia.

O presente trabalho abordará de forma inteligente e concisa em tópicos as 9 dimensões da certificação após dar uma breve e clara introdução sobre cidades sustentáveis e a situação geral em que o planeta e o país se encontra. No primeiro 
tópico Processo Integrativo (IP), falará da importância de apoiar resultados de alto desempenho e custo efetivo através de uma análise inicial de inter-relações entre a cidade ou os sistemas comunitários. No tópico Sistemas Naturais e Ecologia (NS), dirá sobre avaliar as condições e serviços ecossistêmicos existentes fornecidos por ecossistemas, paisagens construídas e outros espaços abertos para informar o desenvolvimento da cidade, juntamente com os esforços de conservação e restauração.

No terceiro tópico Transporte e Uso da Terra (TR), será pautado sobre promover o transporte não motorizado, incentivar o uso do transporte público e reduzir a poluição do setor de transporte. No tópico seguinte Eficiência Hídrica (WE), fará uma abordagem sobre como proporcionar a todas as seções da sociedade acesso equitativa à água potável, aos serviços de saneamento e evitar a poluição do escoamento de águas pluviais. No quinto tópico, Energia e Emissões de Gases de Efeito Estufa (EN), tratará a respeito de fornecer acesso seguro, confiável, resiliente e equitativo a energia.

No tópico Materiais e Recursos (MR), relatará sobre como gerir de forma eficaz e eficiente os resíduos. Quanto ao tópico Qualidade de Vida (QL), exprimirá sobre a demografia da população e as características da área habitacional. No tópico Inovação (IN), discorrerá sobre como incentivar as cidades a alcançar um desempenho excepcional ou inovador. E por fim, no tópico Prioridade Regional (RP), explicitará sobre proporcionar um incentivo para a obtenção de créditos que atendam a prioridades socioeconômicas e ambientais geograficamente específicas.

Grandes cidades pelo mundo se encontram insustentáveis, necessitando de ações e estudos para que ocorra o desenvolvimento sustentável. Através deste estudo, espera-se incentivar e evoluir a busca por desenvolvimento sustentável, neste caso, sendo direcionado e aprofundado pela certificação LEED Cidades e Comunidade Existentes, aplicada em diversas dimensões, utilizando-se de pesquisa bibliográfica através de análise de livros, artigos científicos, dissertações de mestrado e sites onde possui a explanação e aplicação da certificação LEED Cidades e Comunidades Existentes. 


\section{LEED FOR CITIES AND COMMUNITIES EXISTING}

O principal sistema de classificação e programa de certificação internacional para avaliar a sustentabilidade e qualidade de vida em uma cidade ou comunidade é o LEED for Cities and Communities Existing (Cidades e Comunidades Existentes). Com o objetivo de transformar cidades mais sustentáveis, equitativas e resilientes em todo o mundo, o sistema engloba medidas de desempenho econômico, social, ambiental e proporciona uma abordagem orientada por dados para avaliar o progresso.

O programa foi projetado para ser aplicável em todas as fases do ciclo de vida de uma cidade ou comunidade. Cidades novas ou em desenvolvimento, cidades existentes, bairros ou distritos em redesenvolvimento. O programa garante uma nova geração de lugares saudáveis, inclusos e prósperos que oferecem às empresas e pessoas um ambiente em que prosperar. O programa afirma que cidades e comunidades irão regenerar e sustentar a saúde e vitalidade de toda a vida dentro de uma geração. $O$ sistema de classificação apoia a Organização das Nações Unidas para a Sustentabilidade. Possui Metas de Desenvolvimento para os ambientalmente sensíveis, socialmente responsáveis e comunidades economicamente viáveis (U.S. GREEN BUILDING COUNCIL, 2019).

O programa LEED for Cities and Communities pode ser usado tanto para governos locais quanto para o setor privado alcançar seus objetivos. Porém o principal solicitante deve ser o corpo governante de uma cidade ou município. No que se refere a comunidades, será aplicado em áreas fora da cidade, como distritos, bairros, zonas econômicas, instalações militares e regiões. Exemplos de candidatos ao sistema de certificação Cities and Communities Existing: um gerente da cidade representando uma cidade em rápido crescimento, um planejador do setor privado que desenvolve uma nova cidade ou comunidade, um desenvolvedor local trabalhando em um bairro ecológico ou em vários edifícios em um local ou bloco urbano dentro de uma cidade antiga, uma autoridade habitacional ou um grupo local que desenvolve um bairro e campus e comunidades educacionais, institucionais ou industriais (U.S. GREEN BUILDING COUNCIL, 2019). 
Para fazer o pedido de certificação o solicitante deverá inscrever o projeto no site da instituição e fazer o upload de toda a documentação oferecendo as informações necessárias (pré-requisito e crédito). O órgão de certificação do sistema de classificação LEED, realizará as revisões de certificação, de acordo com o Guia de Certificação para Cidades e Comunidades (GBCl). O total de pontos disponíveis são 110 e o mínimo necessário para a certificação é de 40 pontos. O sistema LEED tem quatro níveis certificação, dependendo dos limiares obtidos: Certified, para a pontuação que ficar entre quarenta e quarenta e nove; Silver, para a pontuação que ficar entre cinquenta e cinquenta e nove; Gold, para a pontuação que ficar entre sessenta e setenta e nove e Platinum, para a pontuação que ficar com oitenta ou mais.

Segundo U.S. Green Building Council (2019) a tipologia Cidades e Comunidades Existentes, da qual possui 9 dimensões para serem analisadas. Todas possuem prérequisitos (práticas obrigatórias) e créditos (recomendações) que conforme são atendidos, asseguram pontos para a edificação. São elas, Processo Integrativo (IP), Sistemas Naturais e Ecologia (NS), Transporte e Uso da Terra (TR), Eficiência Hídrica (WE), Energia e Emissões de Gases de Efeito Estufa (EN), Materiais e Recursos (MR), Qualidade de Vida (QL), Inovação (IN) e Prioridade Regional (RP).

\subsection{PROCESSO INTEGRATIVO (IP)}

O mundo está experimentando um rápido crescimento urbano. Projeta-se que até 2030, 60\% da população mundial esteja ocupando as cidades. As cidades são responsáveis por $75 \%$ do produto interno bruto (PIB) mundial, $75 \%$ de dióxido de carbono e consumidora de $75 \%$ dos recursos naturais globais. Do mesmo modo as cidades possuem o potencial e poder para que este crescimento seja inteligente, conservando o ecossistema ao mesmo tempo em que cresce economicamente (U.S. GREEN BUILDING COUNCIL, 2019).

Segundo Leite (2012, p. 20):

Desde 2007 o mundo presencia uma realidade nova, historicamente radical: há mais gente nas cidades do que no campo. Há cem anos, 
apenas $10 \%$ da população mundial vivia em cidades. Atualmente, somos mais de $50 \%$, e até 2050 seremos mais de $75 \%$.

As cidades também são responsáveis por $70 \%$ das emissões de gases de efeito estufa e somente ocupam 2\% da área terrestre do mundo. Desta porcentagem, 30\% são geradas por edifícios, pelos os blocos de construção das cidades. Deste modo, os edifícios verdes são um ingrediente essencial da estratégia de uma cidade para o desenvolvimento sustentável. A classificação LEED for Cities é um sistema que abrange estratégias de nível macro, enquanto os edifícios verdes apoiam as estratégias de nível micro ajudando a tornar as cidades mais sustentáveis. Edifícios públicos verdes ajudam a dar um bom exemplo de políticas e incentivos de construção verde impulsionando o desenvolvimento futuro com estratégias de longo prazo das cidades (U.S. GREEN BUILDING COUNCIL, 2019).

Sendo assim, o processo integrativo (IP) possui créditos de Planejamento Integrativo e Liderança e Política de Incentivos de Construções Verdes. O primeiro crédito tem o intuito de organizar e unir todo esse sistema em um ciclo participativo de análise apoiando resultados de alto desempenho e custo efetivo através de uma análise inicial de inter-relações entre os sistemas da cidade ou comunidade. Realiza-se reuniões regulares com uma equipe integrativa, discutindo problemas, formulando soluções, revendo responsabilidades e identificando passos, facilitando assim, o trabalho em equipe para a análise antecipada dos sistemas da cidade trazendo resultados econômicos e de alto desempenho.

O segundo crédito vem a incentivar o projeto, a construção e a reforma de edifícios usando práticas de construções ecológicas. Ele analisa e incentiva algumas opções de requisitos, tais como, os edifícios pertencentes e / ou operados pelo governo local ou autoridade de desenvolvimento, novos edifícios adotando política para todas as novas construções realizadas pelo governo da cidade ou autoridade local da comunidade para obter o LEED ou uma certificação de construção verde equivalente, edifícios pertencentes e/ou operados pelo governo local ou autoridade de desenvolvimento e edifícios de propriedade privada. 


\subsection{SISTEMAS NATURAIS E ECOLOGIA (NS)}

As características ambientais que as cidades e comunidades possuem são analisadas por uma avaliação do ecossistema, identificando ativos, como áreas úmidas favoráveis, lagos, córregos, costas, íngremes declives e populações de plantas saudáveis, bem como passivos, tais como solos insalubres, estruturas deterioradas, fontes de poluição e qualidade da água (U.S. GREEN BUILDING COUNCIL, 2019).

Nesse contexto Huw Heywood destaca:

O ecologista Barry Commoner nos deu esta regra. Os ecossistemas terrestres, comunidades de organismos vivos (flora e fauna) e seus ambientes inorgânicos (ar, água, terra), fornecem tudo o que é necessário para a vida do planeta, desde o ar e água limpa até alimentos, combustíveis, medicamentos, materiais de construção, sumidouros de carbono e polinizadores. A ecosfera é a estrutura autossuficiente de ecossistemas e é descrita como sendo composta de quatro domínios ou "esferas" fundamentais: atmosfera, biosfera, hidrosfera e geosfera. Precisamos readquirir uma compreensão adequada da dimensão dessa interconectividade, da qual a vida depende. (HEYWOOD, 2017, p.102)

Os espaços verdes fornecem um importante espaço para a construção da comunidade para que as pessoas possam se reunir, brincar, se exercitar, celebrar, aprender, relaxar, refletir e desfrutar da natureza e da vida da cidade.

O verde é a cor mais fácil para a percepção visual dos seres humanos, devido à sua posição do espectro e à anatomia do olho humano. Por esse motivo, o verde é uma cor relaxante, tornando-se um antídoto essencial para as nossas vidas atribuladas. Disponibilize espaços verdes com tratamento paisagístico, não importa o quão pequenos, para oferecer uma alternativa que sirva como um alívio do barulho e da poluição de nossas cidades frenéticas. (HEYWOOD, 2017, p.156) 
O uso inadequado ou excessivo de luz artificial, conhecido como poluição luminosa, pode ter sérios danos ambientais, como também, consequências para os seres humanos, para a vida selvagem e também o clima. Grande parte da iluminação externa usada à noite é ineficiente, excessivamente brilhante, mal direcionada, em muitos casos, completamente desnecessária. Toda esta luz e a eletricidade estão sendo desperdiçadas em vez de se concentrar em áreas específicas que precisam com muito mais urgência e importância serem iluminadas (U.S. GREEN BUILDING COUNCIL, 2019).

Estamos na era de mudanças climáticas e seus impactos. Sinais comuns de mudança climática incluem temperaturas médias anuais mais altas, elevação do nível do mar e clima extremo. Alguns impactos mais fortes podem envolver enchentes, secas, ondas de calor prolongado e aumento da frequência de eventos de tempestade perigosos. Estes impactos podem mudar radicalmente ecossistemas, desestabilizar economias e ameaçar a qualidade de vida.

Segundo André Trigueiro as duas maiores cidades do país, São Paulo e Rio de Janeiro já estão sentindo os impactos destas mudanças realizados por estudos de universidades e instituições de pesquisas do Brasil.

[...] No caso de São Paulo, o estudo revela que a cidade já sofreu várias mudanças importantes no clima nos últimos setenta anos. Nesse período, segundo o pesquisador Carlos Nobre, do instituto nacional de Pesquisas Espaciais (Inpe), a temperatura da cidade subiu 2,5ㄷ e as descargas elétricas (raios) aumentam entre 30\% e 40\% por causa do aquecimento. As chuvas intensas também acontecem com mais frequência (duas a quatro vezes mais) do que há setenta anos. [...] No caso do Rio de Janeiro, o relatório prevê três diferentes cenários de elevação do nível do mar na zona costeira do Rio de janeiro, avançando por áreas de baixada: elevação de 0,50 m, $1 \mathrm{~m}$ e 1,50 m de altura. (TRIGUEIRO, 2017, p.143-144). 
Sendo assim, Sistemas Naturais e Ecologia (NS), possui Pré-requisito de Avaliação de Ecossistemas e Créditos de Espaços Verdes, Conservação de Recursos Naturais e Restauração, Redução da Poluição Luminosa e Planejamento de Resiliência. O intuito do pré-requisito Avaliação de Ecossistemas é avaliar as condições e serviços ecossistêmicos existentes fornecidos por ecossistemas, paisagens construídas e outros espaços abertos para informar o desenvolvimento da cidade, juntamente com os esforços de conservação e restauração. A avaliação possui requisitos que incluem os tópicos Topografia, Solos, Vegetação e Habitat e por fim, Hidrologia e Ecossistemas Aquáticos.

A finalidade do Crédito Espaços Verdes é proporcionar espaços verdes acessíveis para impactar positivamente a saúde física, mental, psicológica e bem-estar da comunidade e, ao mesmo tempo, melhorar a qualidade ambiental da cidade ou comunidade fornecendo espaço verde de fácil acesso. O objetivo do Crédito Conservação de Recursos Naturais e Restauração, é conservar e restaurar os recursos naturais dentro da cidade ou comunidade.

A intenção do Crédito Redução da Poluição Luminosa é minimizar e gerenciar os níveis de luz ambiente para proteger a saúde pública e a integridade dos sistemas aumentando o acesso ao céu noturno e consequentemente a visibilidade noturna. $O$ crédito requer o cumprimento de normas para reduzir a poluição luminosa e limitar seus efeitos negativos. O intuito do Crédito Planejamento de Resiliência é fortalecer a resiliência das comunidades aos riscos das alterações climáticas, dos riscos naturais e eventos extremos.

\subsection{TRANSPORTE E USO DA TERRA (TR)}

VMT (milhas do veículo percorridas) é um indicador padrão que mede a quantidade de milhas percorridas em uma região geográfica durante um determinado período de tempo. As cidades e comunidades que são compactas oferecendo caminhadas seguras, confortáveis e acessíveis, como o ciclismo e infraestrutura de transporte público como consequência têm menor quilometragem de veículo percorrida. Desta 
forma, ocorre a redução dependência de veículos motorizados, redução das emissões de GEE e melhoria da saúde pública (U.S. GREEN BUILDING COUNCIL, 2019).

Diferentes pesquisas confirmam que, entre todos os combustíveis, o diesel é o maior vilão para a saúde. Ônibus e caminhões movidos a diesel representam só $10 \%$ dos veículos no Brasil (aproximadamente 2,3 milhões de unidades), mas emitem $50 \%$ da poluição que a população respira - especialmente as partículas finas, mais prejudiciais à saúde. Isso pode causar doenças respiratórias graves e levar até a morte. (TRIGUEIRO, 2017, p.29).

O desenvolvimento em centros e bairros compactos deve ser dimensionados para todos os humanos, universalmente acessíveis que conectam ao transporte público e oferecer diversos usos e serviços. Cidades e comunidades com desenvolvimento denso, compacto e de uso misto são capazes de conter expansão urbana, reduzir a dependência de veículos motorizados e incentivar a caminhada e o ciclismo, aumentando assim a qualidade de vida de todos os cidadãos. As cidades e comunidades devem oferecer múltiplas opções de transporte e incentivar uma mudança para o transporte público que suporte o meio ambiente melhorando assim, a saúde pública. Se as instalações de trânsito forem seguras, confortáveis, atraentes e convenientes, tende a aumentar aproveitamento do transporte público (U.S. GREEN BUILDING COUNCIL, 2019).

[...] Uma definição atual da cidade compacta pode considera-la como um modelo de desenvolvimento urbano que promova altas densidades (maior do que 250 habitantes por hectare) de modo qualificado, ou seja, com adequado e planejado uso misto do solo urbano, misturando funções urbanas (habitação, comércio e serviços). É baseado em um eficiente sistema de mobilidade urbana que conecte esses núcleos de sistemas adensados e, além da eficiência de transportes públicos, tenha um traçado urbano que encoraje a caminhada e o ciclismo. (LEITE, 2012, p.158). 
Os EUA que possui a maior parte das emissões totais de GEE, em 2016 o transporte representou 28\% dessas emissões. Emissões estas que prejudicam a saúde de todos, principalmente de crianças, idosos e outras populações mais sensíveis. As cidades e comunidades devem promover combustíveis alternativos para veículos de menor emissão e não baseados em gasolina, como exemplo, de eletricidade, hidrogênio, propano, gás natural comprimido, gás natural liquefeito, metanol e etanol. Iniciativas como o fornecimento de estações de recarga e reabastecimento, e incentivos fiscais a estes tipos de veículos de sistema de transporte mais ecológico, seriam necessários para um novo investimento e novo modo de vida no transporte (U.S. GREEN BUILDING COUNCIL, 2019).

[...] Cada vez mais, pensa-se a mobilidade urbana como parte integrante da concepção geral de uma cidade sustentável, onde mover-se com qualidade é face da mesma equação em questão habitar com qualidade de vida ou trabalhar com qualidade. Neste sentido, a mobilidade urbana de qualidade estende-se concomitantemente a um adequado sistema de transporte público e as inovadoras possibilidades de locomoção individual. (LEITE, 2012, p.145).

As cidades e comunidades devem incorporar as informações de comunicação tecnológicas para o sistema de transporte através da adoção das estratégias ou políticas de tecnologias inteligentes. Tecnologias como sistemas de informação aos passageiros, cobrança eletrônica, prioridade e sincronização do sinal de trânsito, e a gestão do estacionamento em tempo real ajuda a melhorar eficiência do sistema de transporte (U.S. GREEN BUILDING COUNCIL, 2019).

[...] Em síntese, pode-se considerar a cidade inteligente como o lugar onde as funções básicas da cidade - estabelecer trocas econômicas, sociais e culturais e gerar liberdade de vida e locomoção - são otimizadas por novas formas de tecnologia da informação e comunicação. (LEITE, 2012, p.174). 
Outro ponto importante é reutilizar e adaptar locais históricos, ajudando a desenvolver novamente revitalizando o bairro, traz benefícios sociais e econômicos para a comunidade do entorno. Tais projetos também conseguem economizar os custos visto que já possuem estruturas existentes, reaproveitando-as (U.S. GREEN BUILDING COUNCIL, 2019).

Segundo Leite (2012, p. 94), "As áreas de vocação histórica produtiva, que entraram em declínio com os processos de desindustrialização e reestruturação, podem voltar a entrar em produção, resgatando a sua vocação original."

Deste modo, Transporte e Uso da Terra (TR), possui Pré-requisito de Desempenho de Transporte e Créditos de Compacto, Misto, Desenvolvimento Orientado para o Tráfego, Acesso ao Trânsito de Qualidade, Veículos Alternativos de Combustível, Mobilidade Inteligente e Política de Transporte e Local de Alta Prioridade.

O intuito do Pré-requisito Desempenho de Transporte é promover o transporte não motorizado, incentivar o uso do transporte público e reduzir a poluição do setor de transporte. Este pré-requisito exige que as cidades meçam, monitorem e relatem o desempenho de seu transporte sistema. O Crédito Compacto, Misto, Desenvolvimento Orientado para o Tráfego, tem o objetivo de incentivar o desenvolvimento do uso compacto e misto, o alto nível de conectividade dentro da cidade ou comunidade e incentivar o uso de caminhada e do ciclismo. O Crédito Acesso ao Trânsito de Qualidade, incentiva o uso de diversos modos de transporte para reduzir a dependência de veículos pessoais dentro da comunidade da cidade.

O Crédito Veículos Alternativos de Combustível, tem a finalidade de reduzir a poluição promovendo alternativas aos veículos movidos a combustíveis fósseis. Quanto ao Crédito Mobilidade Inteligente e Política de Transporte, ele promove a operação eficiente dos sistemas de transporte, facilitação do usuário, mudança de comportamento e redução do impacto ambiental através de tecnologias inteligentes e políticas de transporte. Por fim, o Crédito Local de Alta Prioridade tem a finalidade de preservar estruturas e locais históricos, reutilizando e adaptando-os resguardando assim a cultura e revitalizando bairros. 


\subsection{EFICIÊNCIA HÍDRICA (WE)}

As cidades devem garantir acesso à água potável e serviços de saneamento para todos os membros da sociedade. A água potável deve estar de acordo com as normas de qualidade da água para garantir a segurança dos consumidores. A gestão de águas pluviais pela colheita e tratamento do escoamento pode ajudar a reduzir as inundações e a poluição. Além disso, a água recuperada pode ser reutilizada para ajudar a atender a demanda de água da cidade (U.S. GREEN BUILDING COUNCIL, 2019).

[...] O país campeão mundial de água doce (12\% de todas a água superficial de rio estão em nosso país, além dos aquíferos Guarani e Amazônico) destrói nascentes e mananciais, dizima as matas ciliares que protegem as margens dos rios, e lança aproximadamente 5.000 piscinas olímpicas de esgoto in natura todos os dias nos rios, lagos, lagoas e em nosso litoral. (TRIGUEIRO, 2017, p.41).

A água é um recurso essencial dentro do ecossistema geral de uma cidade. Os humanos precisam de água para agricultura, uso doméstico e recreação, entre outros usos. Alguns pesquisadores calcularam que no ano de 2000, 150 milhões de habitantes urbanos residiam em cidades com escassez de água perene, ou seja, menos de 100 litros por pessoa por dia de fluxo sustentável de águas superficiais e subterrâneas dentro de suas extensões. Este número deverá crescer para 993 milhões de pessoas até 2050. Portanto, proteção, reutilização, e o uso eficiente de recursos hídricos para reduzir a pegada hídrica geral da cidade são fundamentais para qualidade de vida (U.S. GREEN BUILDING COUNCIL, 2019).

No que desrespeito a exemplos de bom planejamento hídrico:

A cidade de Santos é apontada por especialistas como uma das que melhor organizaram a distribuição de água potável e a coleta e tratamento de esgoto para a população. Uma das razões para esse reconhecimento vem do planejamento urbano feito no início do século 
passado, quando o sanitarista Saturnino de Brito construiu os "famosos" canais de Santos, e o primeiro sistema de tratamento sanitário da cidade, com dois prédios, que resistem ao tempo e permanece no mesmo lugar. (TRIGUEIRO, 2017, p.53).

Os sistemas inteligentes de água otimizam o desempenho dos serviços de água melhorando a eficiência, a longevidade e a confiabilidade. Estes sistemas também ajudam a melhorar o desempenho geral das redes de abastecimento de água medindo, coletando, e analisando os dados, em seguida, tomando ações corretivas apropriadas. Estes sistemas podem se unir em vários sistemas dentro de uma rede para compartilhar dados entre plataformas. Considerando muitos dos desafios enfrentados pelas concessionárias, incluindo gerenciamento de vazamentos, conformidade com regulamentações e atendimento ao cliente, utilitários podem melhorar o desempenho, integrando sistemas de maneira a rastrear e destacar áreas problemáticas (U.S. GREEN BUILDING COUNCIL, 2019).

O reuso da água caminha a passos lentos no Brasil, se compararmos com outros países (segundo a Go Associados, hoje, menos de $0,1 \%$ da água produzida no país é de reuso; em Cingapura, esse percentual chega a 30\%; em são Paulo, é inferior a $2 \%$ ). Ainda assim, é cada vez maior o número de empresas que transformam o próprio esgoto em água tratada, pronta para ser utilizada das mais diversas maneiras. (TRIGUEIRO, 2017, p.54).

Deste modo, Eficiência Hídrica (WE), possui Pré-requisitos de Acesso à Água e Qualidade e Desempenho da Água. Possui Créditos de Gestão Integrada de Água, Gestão de Águas Pluviais e Sistemas de Água Inteligente.

O primeiro Pré-requisito de Acesso à Água e Qualidade, tem a intenção de proporcionar a todas as seções da sociedade acesso equitativo à água potável e ao saneamento Serviços. Este pré-requisito aborda três questões críticas: acesso a água potável, acesso a saneamento serviços, e prevenção da poluição da descarga de águas residuais e escoamento de águas pluviais. O segundo Pré-requisito 
Desempenho da Água, incentiva as cidades a reduzir seu consumo de água sem comprometer a saúde pública ou as necessidades econômicas.

O Crédito Gestão Integrada de Água vem apoiar a gestão da água, redução do consumo de água doce e encoraja a avançar para uma rede cidade zero de água. Esse crédito incentiva também as cidades e comunidades a reduzirem a dependência de fontes de água não renováveis, como águas subterrâneas e reutilização das águas residuais tratadas e coletadas para atender a demanda. Quanto ao Crédito de Gestão de Águas Pluviais incentiva a redução do volume de escoamento, diminuição da erosão, inundação e recarga das águas subterrâneas. Por fim, o Crédito Sistemas de Água Inteligente tem o objetivo de melhorar a eficiência operacional dos sistemas de gestão de água através da utilização de tecnologia. Esse crédito exige que uma cidade aplique a tecnologia da informação para melhorar a eficiência da água.

\subsection{ENERGIA E EMISSÕES DE GASES DE EFEITO ESTUFA (EN)}

O fracasso em fornecer energia tanto para uma comunidade específica ou para o toda a rede de distribuição prejudica a confiança dos cidadãos e desperdiça dinheiro e recursos. Além disso, um sistema de energia eficiente pode reduzir a probabilidade de falhas no equipamento. Um bom projeto e estratégias podem ajudar a reduzir os custos operacionais e os futuros danos. As cidades cobrem $2 \%$ da área terrestre do mundo, mas são responsáveis por $70 \%$ das emissões de GEE antropogênicas (induzidas pelo homem) no mundo (U.S. GREEN BUILDING COUNCIL, 2019).

O agravamento da crise climática acelera o ritmo das mudanças e nessa corrida contra o tempo para evitar os piores cenários (degelo das calotas polares, elevação do nível do mar, mudança do ciclo da chuva, eventos extremos ainda mais devastadores etc.) testemunhamos o esforço de governos e empresas, movimentos sociais e religiosos, para que não sejam lembrados num futuro próximo como omissos, irresponsáveis ou indiferentes. (TRIGUEIRO, 2017, p.13). 
Existem várias maneiras pelas quais uma cidade ou comunidade pode incorporar energia renovável em seu portfólio de energia. Estes incluem energias renováveis de pequena escala, como a energia fotovoltaica no telhado ou em larga escala, como parques eólicos ligados à rede. Uma abordagem colaborativa entre as cidades e serviços públicos ou prestadores de serviços é fundamental para o sucesso da implementação de soluções de energia renovável (U.S. GREEN BUILDING COUNCIL, 2019).

Se fosse possível aproveitar todas as áreas abertas de insolação do Brasil - excluindo-se as reservas ambientais, comunidades indígenas e quilombolas e outras -, a produção de energia solar fotovoltaica em nosso país seria de aproximadamente 30 mil GW. Isso é duzentas vezes superior à atual matriz elétrica brasileira, que soma $143 \mathrm{GW}$ com todas as fontes de energia incluídas. (TRIGUEIRO, 2017, p.14).

A era pós-industrial é marcada por um aumento das emissões de GEE atribuíveis ao crescimento econômico. O forte acoplamento do crescimento econômico e das emissões de GEE tem sido um dos principais contribuintes para a mudança climática induzida pela humanidade. Como as cidades são os motores do crescimento econômico, elas são obrigadas a estimar Intensidade de GEE da economia e conceber estratégias eficazes para dissociar as emissões de GEE e crescimento (U.S. GREEN BUILDING COUNCIL, 2019).

Hoje, com tecnologia avançada, os consumidores podem fazer escolhas informadas sobre consumo de energia ou até se tornam produtores de energia.

Hoje, com o equipamento convencional, o consumo de energia chega até as concessionárias uma vez por mês, depois que a leitura do medidor é feita. Com a rede inteligente serão pelo menos seis dados analisados em tempo real, que vão permitir aos pequenos consumidores economizar energia e dinheiro. E a eletricidade que eles deixarem de usar poderá ser oferecida a grandes clientes que, por vezes, enfrentam restrições de consumo. (TRIGUEIRO, 2017, p.24). 
Sendo assim, Energia e Emissões De Gases De Efeito Estufa (EN), possui Prérequisitos de Acesso à Energia, Confiabilidade e Resiliência e Energia e Gestão de Emissões de Gás de Efeito Estufa. Possui também Créditos de Eficiência Energética, Energia Renovável, Economia de Baixo Carbono e Harmonização da Rede Elétrica Inteligente.

O Pré-requisito de Acesso à Energia, Confiabilidade e Resiliência tem a intenção de fornecer acesso seguro, confiável, resiliente e equitativo à energia. Este pré-requisito está alinhado com um dos principais alvos do Objetivo de Desenvolvimento Sustentável das Nações Unidas, que apela ao acesso universal a serviços energéticos acessíveis, confiáveis e modernos até 2030. O segundo Pré-requisito, Energia e Gestão de Emissões de Gás de Efeito Estufa tem o intuito de apoiar a gestão de energia para desenvolver um inventário de emissões que pode identificar o mais eficaz baixo-carbono, reduzir a exposição aos riscos da mudança climática, melhorar a segurança energética e ao mesmo tempo, atrair financiamento climático.

O Crédito de Eficiência Energética objetiva melhorar a eficiência energética setorial na cidade. Esse crédito concentra-se na eficiência energética do lado da demanda na cidade. O Crédito de Energia renovável, tem a finalidade de reduzir os danos ambientais e econômicos associados à energia dos combustíveis fósseis e reduzir as emissões de gases de efeito estufa, aumentando o auto abastecimento de energia renovável e o uso de fonte de rede, tecnologias de energia renovável e projetos de mitigação de carbono. Esse Crédito oferece um caminho único para as cidades avaliarem sua eficácia e avançar para a energia renovável. Além disso, o crédito é estruturado para recompensar as cidades com base em seu nível de esforço e o impacto de suas soluções.

O quarto Crédito de Economia de Baixo Carbono designa avançar em direção a uma economia de baixo carbono, dissociando o crescimento econômico da cidade ou comunidade das emissões de gases com efeito de estufa. Por fim, o Crédito de Harmonização de Rede Elétrica Inteligente tem a meta de melhorar a eficiência operacional do sistema energético e incentivar a participação dos consumidores otimizando o uso de energia. Esse crédito exige que a cidade colabore com o utilitário 
ou provedor de serviços para implantar tecnologias avançadas e fornecer um sistema de rede elétrica inteligente (GRID) com baixo impacto ambiental.

\subsection{MATERIAIS E RECURSOS (MR)}

Com uma rápida urbanização, desenvolvimento econômico e crescimento populacional, cada vez mais recursos são necessários para atender a demanda do consumidor. À medida que as nações e as cidades se expandem e crescem, elas precisam oferecer mais serviços para com seus cidadãos e, por sua vez, gerenciar, tratar e dispor de quantidades correspondentes de resíduos. Em todo o mundo, quase $40 \%$ dos resíduos são depositados em aterros. Cerca de 19\% são recuperados através de reciclagem e compostagem, e 11\% são tratados através de incineração moderna (U.S. GREEN BUILDING COUNCIL, 2019).

Segundo André trigueiro especialista em gestão ambiental pela COPPE/UFRJ:

Um dos efeitos colaterais mais perversos da sociedade de consumo onde se privilegia a cultura do descartável e do perecível - é a gigantesca quantidade de lixo gerada no mundo inteiro. São aproximadamente 10 bilhões de toneladas de resíduos por ano, com graves impactos sobre saúde, a economia e o meio ambiente. A ONU estima que 3 bilhões de pessoas sejam diretamente atingidas pela falta de sistemas inteligentes de coleta, transporte e destinação final do lixo. (TRIGUEIRO, 2017, p.159).

Em todo o mundo, as taxas de geração de resíduos estão aumentando. Em 2016, as cidades do mundo geraram 2,01 bilhões de toneladas de resíduos sólidos, totalizando uma pegada de 0,74 quilogramas por pessoa por dia. Com o florescimento população e urbanização rápida, espera-se que a geração anual de resíduos aumente em 70\% a partir de 2016 para 3,4 bilhões de toneladas em 2050. Os resíduos sólidos urbanos são um dos vários fluxos de resíduos geridos pelas cidades. Em 2016, o Banco Mundial relatou geração global de resíduos industriais $12,73 \mathrm{~kg}$ per capita por dia, 
biomédico como $0,25 \mathrm{~kg}$ e lixo eletrônico como 0,02 kg (U.S. GREEN BUILDING COUNCIL, 2019).

A geração de resíduos no Brasil cresce em ritmo acelerado, superior ao crescimento populacional. No período de 2014 a 2015, a população cresceu $0,8 \%$, ao passo que a taxa de resíduos foi de $1,7 \%$, mesmo com retração de 3,8\% no PIB (IBGE, 2016). Em 2015, foram geradas 79,9 milhões de toneladas de resíduos, das quais $41,3 \%$ tiveram destino inadequado em lixões e aterros controlados e $58,7 \%$ foram destinam aos aterros sanitários (Abrelpe, 2016). (POLZER, 2018, p.964, apud IBGE, ABRELPE).

O desperdício de comida no Brasil é gigantesco, daria apara alimentar aproximadamente 30 milhões de pessoas, equivalente por exemplo, a população do país como o Iraque. Cada ser humano gera em média, $1 \mathrm{~kg}$ de lixo por dia, sendo que mais da metade é matéria orgânica, como consequência, 22 milhões de toneladas de alimentos vão parar na lixeira na maioria das cidades brasileiras (TRIGUEIRO, 2017).

[...] foram recolhidas das ruas, praias, encostas e outros lugares da cidade onde não deveria haver lixo nenhum, mais de 1 milhão e 225 mil toneladas de resíduos. O equivalente a três estádios do Maracanã repletos de lixo, do chão até o teto. (TRIGUEIRO, 2017, p.159).

No entanto, Materiais e Recursos (MR), possui Pré-requisitos de Gerenciamento de Resíduos Sólidos e Performance de Resíduos. Possuem Créditos de Gestão Especial de Fluxos de Resíduos, Fornecimento Responsável para a Infraestrutura, Recuperação de Material e Sistemas Inteligentes de Gerenciamento de Resíduos.

O primeiro Pré-requisito de Gerenciamento de Resíduos Sólidos tem a intenção de gerir de forma eficaz e eficientemente os resíduos na cidade. Para resolver estes problemas, este pré-requisito encoraja gestão eficaz, eficiente e sistemática de resíduos, permitindo que as cidades busquem resíduos sustentáveis e métodos de gestão através de compostagem, reciclagem e eliminação segura. No segundo Pré- 
requisito de Performance de Resíduos, este apoia a gestão de resíduos e o avanço para a cidade de resíduos líquidos zero. Como esses fluxos de resíduos são muitas vezes negligenciados por muitas cidades, este pré-requisito exige que a cidade calcule a geração total de resíduos e o desvio de resíduos para todos fluxos de resíduos.

No primeiro Crédito de Gestão Especial de Fluxos de Resíduos, visa desviar os fluxos de resíduos especiais de aterros e incineradores, recuperando, reciclando e reutilizando os materiais. O desvio deve ser medidos e reportados para todos os resíduos especiais gerados e desviados anualmente. No segundo Crédito de Fornecimento Responsável para a Infraestrutura, ele incentiva o uso de produtos e materiais para os quais a informação do ciclo de vida esteja disponível e foi extraído e originado de forma responsável.

No terceiro Crédito de Recuperação de Material, apoia a recuperar materiais do fluxo de resíduos que tenham um valor alto e forneçam um mecanismo para recolha e canalização destes de volta para o produtor, movendo-se para uma economia circular. Esse crédito estimula a recuperação de material do fluxo de resíduos e mecanismos de coleta e retorno desses materiais de volta ao produtor. Através de programas estendidos de responsabilidade do produtor e relatórios de resíduos não recicláveis, este crédito incentiva as cidades a fechar o circuito de material para uma economia circular.

Por fim, o último Crédito de Sistemas Inteligentes de Gerenciamento de Resíduos objetiva melhorar a eficiência operacional do sistema de gestão de resíduos. Este crédito incentiva as cidades a melhorarem eficiência global dos sistemas de gestão de resíduos através de tecnologias inteligentes abrangentes, como sistemas de transporte pneumático, software baseado em nuvem conectado à Internet das Coisas (Internet of Things - IOT), inteligente sensores e tecnologia de escaninho inteligente. 


\subsection{QUALIDADE DE VIDA (QL)}

A Qualidade de Vida abrange uma série de tópicos críticos, incluindo saúde humana, educação, habitação, condições, direitos civis e segurança. Dada a escala das cidades e comunidades e a variação em sua história, cultura e condição econômica, entender como a melhoria está sendo feita nos principais indicadores é valiosa para refletir a eficácia das ações. Enfrentar estas questões agora fortalecerá a qualidade de vida para o futuro gerações e sua capacidade de prosperar (U.S. GREEN BUILDING COUNCIL, 2019).

Há uma conexão entre um estilo de vida urbano ativo e a qualidade da saúde humana. Em muitas cidades modernas, monocêntricas e dependentes de carros, o fácil acesso a oportunidades seguras de realização de atividade física diária é bastante limitado. Ao mesmo tempo que disponibilizam ambientes densos e compactos para a vida e o trabalho urbanos, as cidades devem permitir a prática de atividades físicas regulares para toda sociedade. As pessoas usarão seus pés se o espaço público for atraente: projete oportunidades para se exercitarem e praticarem a pé e de bicicleta, para se exercitarem tanto esporte como jardinagem e o cultivo urbano da terra. (HEYWOOD, 2017, p.168).

A justiça ambiental está enraizada na crença de que todas as pessoas, independentemente de raça, etnia, gênero ou renda, tenham o direito a um ambiente limpo e saudável para viver, trabalhar, estudar, brincar e orar. Embora a definição de justiça ambiental varie, a maioria das definições inclui três elementos: distribuição, procedimento e processo (U.S. GREEN BUILDING COUNCIL, 2019).

[...]Contraditoriamente, a realidade das cidades brasileiras demonstra empiricamente que as práticas de planejamento urbano no Brasil têm excluído de seus processos as amplas camadas da população, na medida em que essas não são devidamente representadas amiúde nas suas etapas de definição, elaboração, implementação e avaliação. A representação política formal por parte do poder legislativo local, embora 
esteja ao abrigo institucional, não se constitui em uma prática inclusiva por não refletir as particularidades requeridas pelo planejamento e pelas políticas públicas urbanas. Ao contrário, o Planejamento Urbano tem favorecido os grupos sociais economicamente privilegiados[...] (FARIA; FERNANDES, 2019, p.26).

Muitas áreas hoje enfrentam problemas com os altos preços na habitação, especialmente aquelas que tiveram sucesso na construção de uma economia vibrante e bairros e centros da cidade. Sem estratégias específicas, as áreas acessíveis tornam-se muito caras para famílias de renda baixa e moderada, potencialmente forçando-os a buscar moradia mais barata na periferia urbana. Isto resulta em custos de transporte para indivíduos e famílias, aumento do tráfego, poluição do ar, mudanças no clima e impactos negativos para a saúde pública e a qualidade de vida (U.S. GREEN BUILDING COUNCIL, 2019).

A equidade, um dos três pilares da sustentabilidade, está em falta em nossas cidades: elas estão se tornando mais desiguais, e não o contrário. Cada cidadão deveria poder participar plenamente de todas as oportunidades que a urbe tem a oferecer, com auxílio de uma liderança municipal em busca de justiça, moradia, abrigo, saúde, educação, ambientes e oportunidades justos e igualitários para todos. As vozes das pessoas devem ser ouvidas e respeitadas desde o início se o desenvolvimento urbano pretende ser sustentável. A cidade, suas instituições democráticas e suas formas construídas devem ser inclusivas e acessíveis a todos em uma sociedade humanista. (HEYWOOD, 2017, p.180).

Os governos locais e as autoridades de desenvolvimento tomam decisões, gastos e investimentos que afetam a sustentabilidade da comunidade. A força da tomada de decisão local é formada por contribuição da comunidade, esforços de planejamento público, regulamentos e coordenação interna entre departamentos e agências (U.S. GREEN BUILDING COUNCIL, 2019). 
Por tanto, Qualidade de Vida (QL), possui Pré-requisitos de Avaliação Demográfica e Desempenho de Qualidade de Vida. Possui também, Créditos de Melhorias na Tendência, Equidade de Distribuição, Justiça Ambiental, Acesso a Habitação e Transporte, Engajamento Cívico e Comunitário e Direitos Civis e Humanos.

No primeiro Pré-requisito de Avaliação Demográfica possui a intenção de descrever a demografia da população e as características da área habitacional. Este requisito inclui a composição de grupos socioculturais e a distribuição dos principais ativos fundacionais. No segundo Pré-requisito de Desempenho de Qualidade de Vida, visa rastrear e medir métricas relacionadas à elevação dos padrões de vida de todas as pessoas. No primeiro Crédito de Melhorias na Tendência, procura demonstrar uma melhoria ao longo do tempo nas principais métricas relacionadas à qualidade de vida de uma pessoa. Neste crédito, os candidatos podem selecionar até quatro indicadores-chave para mostrar melhoria demonstrada no ano de referência mais recente a partir de um ano de referência, não mais do que cinco anos anteriores.

No segundo Crédito de Equidade de Distribuição, promove a prosperidade econômica equitativa e ampliação do acesso a serviços comunitários para todos. No Crédito de Justiça Ambiental, ele aborda as condições que podem levar os bairros ou populações a serem sobrecarregados por poluentes ambientais. Quanto ao Crédito Acesso a Habitação e Transporte, tem o objetivo de construir, preservar e manter uma oferta adequada e diversificada de opções de moradia econômicas e acessíveis para todos os residentes, inclusive atendendo às necessidades de pessoas que são de baixa renda ou que vivem em situação de rua.

No que desrespeito ao Crédito Engajamento Cívico e Comunitário, vem a promover uma comunidade coesa e socialmente conectada para facilitar sua participação em comunidades locais tomando decisões. Para este crédito, os candidatos devem demonstrar uma combinação de alta tecnologia (digital) e alto contato (direto engajamento) técnicas utilizadas para envolver todos os residentes. Os pontos são creditados com base na conquista de até duas de quatro opções adicionais: representação comunitária diversificada, senso de empoderamento, coesão e conectividade, e taxa de voluntariado. 
Por fim, o Crédito Direitos Civis e Humanos, procura manter um processo que garanta os direitos civis e humanos de todas as pessoas. Esse crédito exige a implementação de todas as quatro ações: adoção de uma lei abrangente local política de oportunidade aplicável ao emprego, moradia e acomodações públicas; atividades para garantir direito ao voto; policiamento comunitário e iniciativas de justiça processual; e uma entidade responsável pelos direitos humanos.

\subsection{INOVAÇÃO (IN)}

O design e a arquitetura sustentável são impulsionados por estratégias inovadoras, bem como esforços excepcionais que vão além dos limites. Quando as cidades inovam e vão além dos requisitos LEED, elas não apenas, podem alcançar benefícios ambientais mensuráveis, além daqueles especificados pelo sistema de classificação LEED, mas também ter a oportunidade de explorar novos conceitos e ideias que possa vir contribuir para o desenvolvimento de futuros Créditos LEED (U.S. GREEN BUILDING COUNCIL, 2019).

A segunda Revolução industrial, que transformou a sociedade a partir de meados do século 19, se caracterizou pelo novo papel atribuído à ciência de promover a inovação tecnológica. A mente humana deixou de ser apenas um elemento de decisão dentro do sistema produtivo e passou a ser força direta da produção. Os conhecimentos científicos tornaramse os principais artifícios de sustentação e de direção do desenvolvimento tecnológico. As inovações tecnológicas passaram a ser o elemento crucial em uma economia baseada cada vez mais no desenvolvimento do conhecimento. (LEITE, 2012, p. 88)

Deste modo, Inovação (IN), possui o Crédito de Inovação, com o intuito de incentivar as cidades a alcançar um desempenho excepcional ou inovador. 


\subsection{PRIORIDADE REGIONAL (RP)}

Os projetos LEED são projetados, construídos e operados em muitos contextos diferentes, tais como, clima, densidade populacional e os regulamentos locais fazendo com que mude significativamente de um local para outro. Os projetos LEED podem ser mais transformadores se as equipes reconhecerem as questões ambientais prioritárias da localidade e abordá-las por meio de projeto, construção e operação (U.S. GREEN BUILDING COUNCIL, 2019).

O historiador Roy Porter escreveu "quando as edificações têm precedência sobre as pessoas, recebemos uma herança, não uma história". Uma cidade sustentável existe para seus cidadãos e deve combinar satisfatoriamente $\mathrm{o}$ antigo e o novo, mantendo sua vitalidade $\mathrm{e}$ conectando o passado e o futuro de um modo significativo. A herança construída na cidade deve fazer parte de uma colagem em constante desenvolvimento, demandando avaliações contemporânea dos aspectos históricos que pretendemos conservar e de como fazê-lo. (HEYWOOD, 2017, p.166).

Por tanto, Prioridade Regional (RP), possui o Crédito Prioridade Regional, com o objetivo de proporcionar um incentivo para a obtenção de créditos que atendam a prioridades socioeconômicas e ambientais geograficamente específicas.

\section{CONSIDERAÇÕES FINAIS}

A cidade sustentável é aquela que necessita satisfazer aos objetivos ambientais, sociais, culturais, políticos, econômicos e físicos de seus cidadãos. O modelo de desenvolvimento urbano nos dias de hoje, não procura atender quanto ao balanceamento dos recursos de forma eficiente. A cidade é muito mais do que apenas edifícios sustentáveis, deve incorporar parâmetros de sustentabilidade no desenvolvimento e na gestão urbana. Diversos estudos no decorrer destas últimas décadas, mostram que a atual trajetória econômica, demográfica e ecológica é insustentável. 
Desta forma, o presente trabalho buscou mostrar uma poderosa ferramenta capaz de transformar cidades através de projetos, obras e operações com o intuito em sustentabilidade e propensão ambiental. Através da certificação internacional LEED (Leadership in Energy and Environmental Design), objetivou-se mostrar a possibilidade de transformar ou criar cidades verdes, inclusivas, resilientes e inteligentes, trazendo assim, benefícios econômicos, sociais e ambientais. Sendo assim, foi abordada a tipologia Cidades e Comunidades Existentes, da qual possui 9 tópicos que foram analisadas dentre pré-requisitos (práticas obrigatórias) e créditos (recomendações).

No primeiro tópico, Processo Integrativo (IP), através dos créditos de Planejamento Integrativo e Liderança e Política de Incentivos de Construções Verdes, foi falado da importância de apoiar resultados de alto desempenho e custo efetivo através de uma análise inicial de inter-relações entre a cidade ou os sistemas comunitários.

No segundo tópico, Sistemas Naturais e Ecologia (NS), por meio de Pré-requisito de Avaliação de Ecossistemas e Créditos de Espaços Verdes, Conservação de Recursos Naturais e Restauração, Redução da Poluição Luminosa e Planejamento de Resiliência, foi dito sobre avaliar as condições e serviços ecossistêmicos existentes fornecidos por ecossistemas, paisagens construídas e outros espaços abertos para informar o desenvolvimento da cidade, juntamente com os esforços de conservação e restauração.

No terceiro tópico, Transporte e Uso da Terra (TR), mediante Pré-requisito de Desempenho de Transporte e Créditos de Compacto, Misto, Desenvolvimento Orientado para o Tráfego, Acesso ao Trânsito de Qualidade, Veículos Alternativos de Combustível, Mobilidade Inteligente e Política de Transporte e Local de Alta Prioridade, foi pautado sobre promover o transporte não motorizado, incentivar o uso do transporte público e reduzir a poluição do setor de transporte.

No quarto tópico, Eficiência Hídrica (WE), através dos Pré-requisitos de Acesso à Água e Qualidade e Desempenho da Água e Créditos de Gestão Integrada de Água, Gestão de Águas Pluviais e Sistemas de Água Inteligente foi feita uma abordagem 
sobre como proporcionar a todas as seções da sociedade acesso equitativo à água potável, aos serviços de saneamento e evitar a poluição do escoamento de águas pluviais.

No quinto tópico, Energia e Emissões de Gases de Efeito Estufa (EN), por meio de Pré-requisitos de Acesso à Energia, Confiabilidade e Resiliência e Energia e Gestão de Emissões de Gás de Efeito Estufa e Créditos de Eficiência Energética, Energia Renovável, Economia de Baixo Carbono e Harmonização da Rede Elétrica Inteligente, trouxe a respeito de fornecer acesso seguro, confiável, resiliente e equitativo a energia.

No sexto tópico, Materiais e Recursos (MR), mediante Pré-requisitos de Gerenciamento de Resíduos Sólidos e Performance de Resíduos e Créditos de Gestão Especial de Fluxos de Resíduos, Fornecimento Responsável para a Infraestrutura, Recuperação de Material e Sistemas Inteligentes de Gerenciamento de Resíduos, relatou-se sobre como gerir de forma eficaz e eficiente os resíduos.

No sétimo tópico, Qualidade de Vida (QL), através de Pré-requisitos de Avaliação Demográfica e Desempenho de Qualidade de Vida e Créditos de Melhorias na Tendência, Equidade de Distribuição, Justiça Ambiental, Acesso a Habitação e Transporte, Engajamento Cívico e Comunitário e Direitos Civis e Humanos, exprimiuse sobre a demografia da população e as características da área habitacional.

No oitavo e penúltimo tópico, Inovação (IN), por meio de Crédito de Inovação discorreu-se sobre como incentivar as cidades a alcançar um desempenho excepcional ou inovador. E por fim, no último e nono tópico Prioridade Regional (RP), mediante o Crédito Prioridade Regional, explicitou-se sobre proporcionar um incentivo para a obtenção de créditos que atendam a prioridades socioeconômicas e ambientais geograficamente específicas.

Por tanto, grandes cidades pelo mundo se encontram insustentáveis, necessitando de ações e estudos para que ocorra o desenvolvimento sustentável. O objetivo alcançado deste estudo, foi incentivar e evoluir a busca por desenvolvimento sustentável, neste 
caso, sendo direcionado e aprofundado pela certificação LEED Cidades e Comunidades Existentes. Através de suas nove tipologias com pré-requisitos e créditos a cidade se torna verde, inclusiva, resiliente e inteligente, trazendo consequentemente, benefícios econômicos, sociais, culturais, políticos, ambientais para a sociedade, levando deste modo, qualidade de vida aos seus cidadãos.

\section{REFERÊNCIAS}

ARAÚJO, Gisele. Estratégias de Sustentabilidade: aspectos científicos, sociais e legais, contexto global e visão comparativa. São Paulo: Editora Letras Jurídicas, 2008.

CORTESE, Tatiana; KNIESS, Cláudia; Maccari, Emerson (Orgs.). Cidades Inteligentes e Sustentáveis. Barueri: Manole, 2017.

GBC BRASIL. Construindo um Futuro Sustentável. 2019. Disponível em: <http://www.gbcbrasil.org.br/>. Acesso em 04 jun. 2019.

HEYWOOD, Huw. 101 Regras Básicas para Edificações e Cidades Sustentáveis. São Paulo: Gustavo Gili, 2017.

JONES, Van. The Green Collar Economy: how one solution can fix our two biggest problems. New York: HarperCollins Publishers, 2009.

JR, Arlindo (Coord.). Gestão Urbana e Sustentabilidade. Barueri: Manole, 2019.

LEITE, Carlos; AWAD, Juliana. Cidades Sustentáveis Cidades inteligentes: desenvolvimento sustentável num planeta urbano. Porto Alegre: Bookman, 2012.

MOSSRI, Beatriz; EUSTAQUIO, Nelson. Pobreza e Exclusão Social. In: Mudanças Globais e Desenvolvimento Sustentável. Brasília: Caderno de Estudo e Pesquisa, 2019.

MOSSRI, Beatriz. Sustentabilidade e Sociedade. Caderno de Estudo e Pesquisa. Brasília, 2018. 
QUERINO, Magda et al. Metodologia da Pesquisa e da Produção Científica. Caderno de Estudo e Pesquisa. Brasília, 2018.

SOBRINHO, Deborah. Cidades Sustentáveis. Caderno de Estudo e Pesquisa. Brasília, 2018.

TRIGUEIRO, André. Cidades e Soluções: como construir uma sociedade sustentável. Rio de Janeiro: Editora LeYa, 2017.

Enviado: Maio, 2020.

Aprovado: Junho, 2020. 